\title{
A ANIMAÇÃO ESTÁ PARA PEIXE: O GÊNERO DE DIVULGAÇÃO CIENTÍFICA NA SÉRIE PEIXONAUTA
}

\author{
ANIMATION IS FOR FISH: THE GENRE OF SCIENCE COMMUNICATION IN THE PEIXONAUTA \\ SERIES
}

LA ANIMACIÓN ES PARA PECES: EL GÉNERO DE LA COMUNICACIÓN CIENTÍFICA EN LA SERIE PEIXONAUTA

\section{Yara Moreira Câmara \\ iD 9 \\ Mestrado em Educação (UFOP) \\ Professora da Rede Municipal de Ouro Preto \\ moreira_yara@yahoo.com.br}

\section{Sheila Alves de Almeida \\ (iD) 9}

Doutorado em Educação

Professora Associada da

Universidade Federal de Ouro

Preto (UFOP)

Docente do Programa de Pós-

Graduação em Educação da

Universidade Federal de Ouro

Preto (UFOP)

sheilaalvez@uol.com.br

\begin{abstract}
Resumo
Este trabalho tem como objetivo investigar a comunicação da ciência na série animada Peixonauta. Para tanto, foi realizada uma análise documental de 27 episódios da segunda temporada da série. Baseado na concepção de ciência, atividade dos cientistas e concepção de infância evidenciou-se que, embora não seja produzido para fins escolares, os objetivos dessa animação são educacionais e seguem a uma tendência que se aproxima, em alguma medida, de concepções escolares de ciência. Embora a vida dos animais seja um aspecto excessivamente explorado nesses materiais, informações sobre os bichos que estão próximos às crianças são pouco frequentes na animação. Reiterase a importância dessa animação como possibilidade de promoção da linguagem de divulgação científica para crianças.

Palavras-chave: Animação. Divulgação científica. Infância.
\end{abstract}

Recebido em: 1 de abril de 2021.

Aprovado em: 16 de junho de 2021.

Como citar esse artigo (ABNT):

CÂMARA, Yara Moreira; ALMEIDA, Sheila Alves de. A animação está para peixe: o gênero de divulgação científica na série Peixonauta. Revista Prática Docente, v. 6, n. 2, e043, 2021. http://doi.org/10.23926/RPD.2021.v6.n2.e043.id1070 


\section{Abstract}

This work aims to investigate the communication of science in the animated series Peixonauta. To this end, a documentary analysis of 27 episodes of the second season of the series was carried out. Based on the conception of science, activity of scientists and conception of childhood, it became evident that, although it is not produced for school purposes, the objectives of this animation are educational and follow a trend that is, to some extent, close to school conceptions of science. Although the life of animals is an aspect that is overexploited in these materials, information about animals that are close to children is infrequent in animation. The importance of this animation is reiterated as a possibility of promoting the language of scientific dissemination for children.

Keywords: Animation. Scientific divulgation. Childhood.

\section{Resumen}

Este trabajo tiene como objetivo investigar la comunicación de la ciencia en la serie animada Peixonauta. Para ello, se realizó un análisis documental de 27 episodios de la segunda temporada de la serie. A partir de la concepción de la ciencia, la actividad de los científicos y la concepción de la infancia, se hizo evidente que, si bien no se produce con fines escolares, los objetivos de esta animación son educativos y siguen una tendencia, en cierta medida, cercana a la escuela. concepciones de la ciencia. Si bien la vida de los animales es un aspecto sobreexplotado en estos materiales, la información sobre animales cercanos a los niños es poco frecuente en la animación. Se reitera la importancia de esta animación como posibilidad de promover el lenguaje de divulgación científica para los niños.

Palabras clave: Animación. Divulgación científica. Infancia. 


\section{INTRODUÇÃo}

A criança do século XXI possui experiência fortemente marcada pela interação com as mídias. Desde as primeiras idades, elas são instigadas à leitura de imagens na televisão, smartphones, notebooks, tablets e tantos outros artefatos que circulam na sociedade. Segundo Bill Green e Chris Bigum (1995, apud HOFFMANN, 2002), as crianças já nascem imersas na cultura da mídia, com uma organização do pensamento advinda dessa vivência.

Mesquita e Soares (2008) destacam que, no Brasil, praticamente, todas as crianças assistem à televisão desde as primeiras idades. Fato compreensível, pois com a falta de recursos econômicos para o acesso a outros bens culturais muitas famílias consideram-na um objeto essencial para o entretenimento e informação. Nesse contexto, a infância se constitui como um público cativo da televisão, tornando-se consumidora em potencial dos produtos veiculados na programação. E, como produto de entretenimento dos canais de televisão, os desenhos animados têm ampla inserção na vida cotidiana das crianças. Como gênero cinematográfico, inevitavelmente associado ao nicho de mercado da indústria de brinquedo, os filmes de animação estão a serviço da construção de mundos imaginários, de personagens com identidade e vida própria que fazem parte da vida cotidiana das crianças, de seus familiares e educadores.

Criados em diferentes momentos históricos e culturais, não se pode perder de vista que cada desenho animado é construído com um enquadramento social tornando-o um veículo de transmissão de valores, de ideologias e de modos de ser e estar na vida e na sociedade. Assim, essa transmissão de conhecimentos e valores é particularmente expressa, de forma mais ou menos explícita, tornando possível a finalidade comunicativa com que são criados ou recriados. É, pois, nesse contexto em que se entendem as animações como veículos importantes para a construção de conhecimentos.

Conforme a literatura, a diversidade de conhecimentos veiculados nos desenhos tem sido objeto de investigação de muitos pesquisadores da indústria de animação e estudos culturais (ALMEIDA, 2011, 2018,.2020; WORTMANN, et. al 2012; SIQUEIRA, 1999; MESQUITA \& SOARES, 2008; TOMAZI, 2009; BUENO, 2012, 2014, VIZACHRI, 2014). Na esteira dessas produções, têm se destacado aquelas que utilizam temas da ciência para comunicar e entreter. Aliás, a relação entre ciência e animação é muito antiga. As imagens de animais e da natureza são frequentemente retratadas nas telas da televisão e do cinema (VIZACHRI, 2014). O Rei Leão, Vida de Inseto, Procurando Nemo, A era do Gelo, Rio; são exemplos de desenhos que utilizam animais e, em alguma medida, apresentam conceitos de 
ciência, ainda que a questão central desses desenhos não seja a comunicação científica para os pequenos. De outro modo, animações como o Show da Luna, De onde vem, Sid - o Cientista, O Laboratório de Dexter. Jimmy Nêutron e Peixonauta são exemplos de produções cujo objetivo é entreter o público infantil com a mediação da linguagem da ciência.

Diante do exposto, o presente estudo procura contribuir com a literatura relativamente à divulgação da ciência para crianças no desenho animado Peixonauta. Considera-se essa animação importante para esta investigação por dois motivos: o alcance na grade de programação da televisão e internet e ser uma série que mostra às crianças fatos e fenômenos do mundo social e natural.

Assim sendo, em pesquisas sobre a divulgação científica para as crianças e a indústria de animação, há estudos que sobre as origens de Peixonauta e a recepção desse desenho pelas crianças. O artigo de Wortmann, et. al (2012), por exemplo, destaca como as questões ambientais são apresentadas às crianças em Peixonauta. E o artigo de Gatti Júnior e colaboradores (2014) aponta as potencialidades da animação no mercado nacional e internacional. Embora esses trabalhos ressaltem o sucesso da animação Peixonauta e sua importância como um recurso importante para a educação, eles não tratam de uma questão importante: quais os aspectos do gênero de divulgação científica para crianças são ressaltados e/ou ignorados na animação? Quais concepções de ciência estão presentes na série Peixonauta? Quais as representações de cientista podem ser observadas no desenho e que atividades são realizadas por eles? Qual a concepção de infância pode ser observada na animação? Para responder a essas questões, realizou-se um estudo minucioso dos personagens da série Peixonauta sendo analisados 27 episódios da segunda temporada da animação. Para isso, foram registrados em uma ficha técnica, inspirada na pesquisa de Tomazi et. al (2009), dados referentes à divulgação científica em filmes de animação infantil. Em seguida, sistematizaramse os aspectos que permitiriam compreender e explicitar algumas características desse produto que o identificam como uma produção de comunicação de ideias científicas para as crianças.

\section{REVISÃo DE LITERATURA}

Em seus estudos sobre divulgação científica para as crianças, Ramos (2014) destaca que esse gênero possui duplo objetivo: o de informar e o de captar a atenção do público infantil. O primeiro é caraterístico do discurso didático, o segundo, um traço próprio do discurso midiático (RAMOS, 2014 p.158). Para Ramos (2014), a divulgação científica para crianças apresenta marcas discursivas bem acentuadas tais como definições, exemplificações e explicações. Nesse 
cenário, o enunciador apresenta-se como portador de um saber estável, não problemático, inquestionável, o que contrasta com o cenário próprio do saber da investigação, que é assumidamente provisório, problemático, discutível (RAMOS, et. al, p.159, 2014). Para Almeida (2011, 2014, 2016) e Ramos (2014), raramente há, no gênero de divulgação científica para crianças, questionamento, controvérsia, divergência de pontos de vista, espaços não preenchidos nas conclusões dos estudos ou até nos seus pressupostos e metodologias. O foco nos resultados, em detrimento dos processos, é outro traço característico do discurso de divulgação científica para as crianças. Por isso, a realidade é apresentada de maneira parcial e superficial. A apresentação de resultados, instantâneos e "úteis", as descobertas e inventos contrastam com a construção do conhecimento científico cujos processos são morosos e, muitas vezes, aparentemente "inúteis", a explicação complexa exige conhecimentos específicos (RAMOS p. 159, 2014).

Como a captação da atenção do público alvo é fundamental, as animações usam, principalmente, efeitos visuais, vivendo sob o permanente risco de ultrapassarem a tênue barreira que separa a divulgação científica do puro espetáculo sensacionalista. Já Bueno (2007), destaca que o "mundo mágico da ciência" nas animações tem sido um prato cheio para trabalhar com crianças. Ela argumenta que a imagem de ciência que a maioria dos desenhos passa é ultrapassada e equivocada. Uma das primeiras questões que se observa nos desenhos é a representação dos cientistas. De acordo com Bueno (2007), as animações geralmente representam os cientistas com jalecos brancos, em laboratórios repletos das mais estranhas geringonças, muitas ferramentas e computadores enfim, criações gigantescas para resolver qualquer problema mirabolante. Em geral, eles são retratados como pessoas dedicadas à ciência que sempre trabalham sozinhos em suas experiências. São personagens que se destacam por sua inteligência e sentem-se diferentes do resto da sociedade. Eles são representados como figura de poder e masculinidade, detentores do conhecimento e da tecnologia para resolver qualquer problema. Na visão de Bueno (2007), a maioria das animações apresenta uma concepção positivista da ciência, que se desenvolve a partir de problemas e está associada à atividade experimental.

Quanto à tecnologia, é apresentada como imprescindível ao progresso e inerente à ciência. Contudo, não abordam os danos causados por esse dito indispensável progresso. Também áreas como linguística, filosofia, geografia e história não fazem parte das "ciências" abordadas pela maior parte dos desenhos e, quando aparecem, não estão ligadas à atividade 
científica, portanto, não são considerados "ciência de verdade". Acrescenta, ainda Bueno (2007), que a ciência retratada na maioria das produções infantis é inquestionavelmente boa, resolve problemas, salva o planeta, traz o progresso. E não raro os personagens justificam suas ações em nome da ciência.

Por fim, Bueno (2007) argumenta que essas produções possuem seu valor, não apenas como entretenimento, mas como material de análise e de questionamento sobre as relações de poder que se estabelecem no mundo da ciência.

Por sua vez, Mesquita e Soares (2008), em seu artigo intitulado "Visões de ciência nos desenhos animados" salientam que, em todas as cenas das animações analisadas, o protagonista neste caso, o cientista, sempre usa um jaleco branco e óculos enormes. O personagem realiza experimentos em seu laboratório e mesmo em suas horas de folga não deixa de lado o interesse pela ciência. O cientista apresenta-se como um gênio solitário em suas atividades. Outra observação destacada pelos autores é a visão de que o desenvolvimento científico é papel exclusivo dos homens. Portanto, os cientistas são frequentemente representados pela figura masculina e, muitas vezes, a mulher é retratada como "do lar" (MESQUITA e SOARES, p. $423,2008)$. Os autores apontaram, ainda, que as produções analisadas mostram a existência de um corpo de cientistas que pesquisam juntos e, possivelmente, chegam a conclusões comuns, o que remete à ideia de ciência consensual. A visão de ciência que se mostra mais evidente nos desenhos é aquela que defende a ciência e as tecnologias dela criadas como solução para os problemas do homem, enfatizando o papel da experiência no desenvolvimento científico (MESQUITA e SOARES, 2008). Essa ênfase na experimentação está associada à importância dada ao laboratório, pois, os personagens, sempre que precisam desenvolver seus experimentos, o fazem em seus laboratórios muito bem equipados.

Concluindo-se, portanto, que a ciência é enaltecida e mitificada por meio de situações, ações e falas dos personagens. A tecnologia é apresentada como elemento que facilita a vida. De acordo com Mesquita e Soares (2008), reconhecer as visões de ciência que permeiam o discurso dos desenhos animados é importante à medida em que esses discursos refletem e influenciam o pensamento das crianças. Nos episódios analisados, a questão de exaltação da ciência, da tecnologia, da dependência da modernização para a resolução de problemas, tende a perpetuar na crença, que ainda existe, de que o progresso é o caminho único para o desenvolvimento humano (MESQUITA e SOARES p. 425 2008). Em alguns episódios dos desenhos animados analisados pelos autores, a ética que envolve o trabalho científico surge 
com enfoque pejorativo, no qual o cientista não leva em conta essas questões envolvidas no procedimento por ele realizado.

\section{A DIVUlgaÇão CIENTÍFICA PARA O PÚBLICO INFANTIL}

Gouvea (2005), em suas investigações, adverte que, ao se produzir um material de divulgação científica para crianças, se deve levar em conta que elas estão em processo de desenvolvimento cognitivo, não têm todas as habilidades e competências desenvolvidas. Por sua vez, em seu trabalho de divulgação científica destinado ao público infantil, Massarani (2007) assinala que diversas pesquisas têm mostrado maior recepção pelas crianças de ideias relacionadas à ciência em comparação com adolescentes e adultos. De acordo com a autora, esse fato, aliado à grande curiosidade infantil, deve ser levado em conta ao empreender iniciativas de divulgação científica para as crianças. No entanto, essa autora ressalta que a linguagem de divulgação científica é uma das maiores preocupações dos autores que produzem materiais para crianças. Massarani (2005) alerta que, em geral, o conteúdo científico destinado às crianças é, em geral, de baixa qualidade, é duvidoso e apresentado de forma inadequada. Em sua opinião, esses materiais não estabelecem relações significativas com o entorno e não favorecem a aquisição de uma visão mais realista da atividade científica. Assim, na maioria das vezes, a informação científica não estimula a curiosidade, nem a interatividade de forma que as crianças possam participar do processo de aprendizado da linguagem das ciências. Para Massarani (2007) a prática de divulgação científica para crianças deve levar em consideração os seguintes recursos:

[...] vínculo con la vida cotidiana; referencia a la cultura popular; apoyo en la historia y en la tradición; vínculo entre arte y ciencia; utilización de analogías y metáforas; desacralización de la ciencia; utilización de ironía y humor; y reconocimiento de los errores humanos. [...] Es preciso también tratar al lector como alguien inteligente, independientemente de su edad. Esto es muy importante ya que hay una tendencia generalizada a dirigirse a los niños de una forma poco adecuada, exagerando el 'infantilismo'. La argumentación usada para menospreciar la capacidad de comprensión de los niños es, en general, el cuestionamiento de si el contenido científico es efectivamente captado por el público. Este es el punto clave de la divulgación científica orientada a cualquier edad y no un problema exclusivo de los niños (MASSARANI, 2007, p.2, grifos da autora).

Massarani considera que, dessa forma, a divulgação científica é um instrumento útil para a educação formal. Em sua opinião, é importante que as crianças tenham acesso à discussão de temas atuais e polêmicos. Desse modo, a ciência não será distante da realidade delas nem será desprezada a capacidade que elas têm de entender temas que envolvam ciência e sociedade para dialogar a respeito. 
Já Giering (2008), em suas análises sobre os discursos que circulam na mídia, destaca que os textos relativos a ciências para as crianças, em sua maioria, apresentam resultados de pesquisa ou de achado científico. Conforme sua análise, esses textos se estruturam a partir do problema que aparece no título, ou no início do texto em forma de pergunta. Daí vem uma explicação - resposta - e, em seguida, a conclusão. O processo para se chegar às explicações fica, em segundo plano, ou simplesmente não aparece. Por isso, as descrições e narrações são mais presentes do que as explicações.

Como divulgador de ciências para crianças, Torok (2008) adverte que os materiais de divulgação científica para crianças precisam descrever o processo, um problema sem solução. A linguagem dos textos deve ser clara e concisa, mas também criativa e colorida. Deve conter informação, evitando jargões. Explicações amparadas por analogias precisam ser apropriadas. Para ilustrar os textos, o autor sugere o uso de fotos em vez de desenhos.

Tendo percorrido algumas ideias acerca da divulgação científica, no tópico seguinte, será realizada uma apresentação da série animada Peixonauta, principal objeto desta reflexão.

\section{O Caso da Série Peixonauta}

A série Peixonauta entrou no ar em 2009, no canal Discovery Kids e o sucesso foi tanto que vários produtos ainda são vendidos com a marca Peixonauta. Atualmente, Peixonauta é transmitido em 67 países. A animação também é sucesso no Sistema Brasileiro de Televisão (SBT), e na internet. O canal do youtube conta atualmente com 356 mil inscritos e alguns desenhos disponíveis nessa plataforma apresentam mais de um milhão de visualizações.

A animação foi desenvolvida com o objetivo de entreter crianças na faixa etária de quatro a sete anos de idade. Na esteira desse sucesso, em 2011, Peixonauta foi estreado no teatro e, em 2012, foi lançado no cinema. A equipe de roteiristas tem formação em comunicação social e mídia educativa. Na ficha técnica da série não foi identificado nenhum especialista em divulgação científica para crianças ou pesquisadores dos temas abordados nos desenhos. Nos episódios analisados, observou-se que as notícias da atualidade, veiculadas na mídia, não constituem o principal critério para a divulgação do conhecimento científico às crianças.

Peixonauta é uma animação computadorizada em planos bidimensionais e utiliza-se da representação de diversos animais a fim de cativar o público presumido. A presença de animais em diferentes biomas parece indicar preocupações de ordem ecológica que, atualmente têm movido a sociedade contemporânea. Aliás, a maioria das cenas da série são representações de paisagens naturais, ambientes com elementos da natureza sem nenhuma intervenção humana 
ou marcas culturais. De acordo com Kindel (2003), nas animações há uma recriação de uma natureza "perfeita" onde os personagens não integram usualmente os contextos. Em Peixonauta, os habitantes de diferentes biomas só aparecem ocasionalmente. No local chamado Parque das Árvores Felizes desenvolvem-se todas as aventuras. Os diversos ambientes representados no parque são apresentados em planos fechados de imagens. A natureza aparece como cenário principal com animais e plantas dotados de pureza e ingenuidade tornando a produção fílmica praticamente inquestionável, corroborando com os estudos de Kindel (2003) sobre a representação da natureza nas animações.

Na série, há personagens que aparecem constantemente nas cenas e têm papéis definidos e outros que compõem o enredo em papéis secundários. Embora a linguagem seja uma característica da maioria dos animais da animação, aqueles que fazem parte do elenco fixo, que protagonizam as histórias são mais antropomorfizados. Segundo Vizachri (2014), a animação é o reino da magia, da emoção e da estética. Ela vigora a relação entre projeção-identificação. Por isso, os animais que interagem com os personagens da série, além da linguagem, apresentam sentimentos e racionalidade humana.

Assim, Peixonauta é um peixe que fala e que se veste com uma roupa parecida com a de um astronauta, daí o seu nome. Ele tem cores fortes, olhos e feições que buscam transmitir simpatia. O seu capacete é um reservatório de água que lhe permite sobrevivência e interação com personagens terrestres. Além da roupa colorida, ele possui vários acessórios que o auxiliam na resolução dos problemas. Diferente dos peixes reais, o corpo de Peixonauta não é o alongado que possibilita a locomoção na água. Mas, ele é capaz de se movimentar tanto em ambientes aquáticos como terrestres. Em terra, ele flutua no ar e se movimenta com o auxílio das nadadeiras.

Embora seja apresentado como um peixe, ele não é representado com escamas, brânquias ou guelras. Em ambientes aquáticos, Peixonauta usa seu escafandro, mas nesses ambientes o capacete aparece aberto. Frequentemente ele aparece reabastecendo seu reservatório de oxigênio no lago indiciando que os peixes precisam da água para respirar. Como Peixonauta é um agente da Organização Secreta para Total Recuperação Ambiental (OSTRA), a sua função é desvendar os enigmas propostos em cada episódio, com o auxílio de outros personagens. Aparece em todos os desenhos com uma bola mágica (POP), que lhe fornece pistas para a solução dos problemas. 
Como se vê, Peixonauta encarna a representação de um cientista, embora não se apresente como tal. Peixonauta não é a figura caricata de cabelo despenteado, óculos fundos e jaleco branco; nem é um gênio solitário trabalhando em um fantástico laboratório repleto de equipamentos complicados. Na série analisada nesta pesquisa, ele é um cientista inventor, um curioso que investiga a natureza. A opção por não explorar a imagem de um velho cientista como protagonista possivelmente deve-se ao público alvo e ao fato de querer passar a ideia de que todo cientista tem curiosidade, um aspecto inerente à infância. Assim, na perspectiva visual, essa animação preocupa-se em trazer à luz o universo de referência do mundo infantil, com a magia de um peixe astronauta e cientista. Peixonauta é um personagem masculino o que pode reforçar a ideia da ciência como uma atividade desse gênero.

Marina é também uma personagem marcante na série. Ela é uma menina com traços finos, com olhos pretos e cabelos lisos, o estereótipo da criança pós-moderna: corajosa, magra, e relativamente independente em relação às figuras parentais que pouco aparecem nos episódios. Frequentemente aparece com uma blusa lilás, uma calça azul, sapatos e relógio. $\mathrm{O}$ cuidado com a aparência é expresso principalmente na vestimenta e no penteado que pode significar marca da produção de uma ideia pré-concebida de feminilidade, que o desenho mostra e reproduz.

Em toda a extensão da animação, Marina aparece ao lado do Peixonauta e de um macaco. Marina e Peixonauta se revezam no papel de destacar a questão-problema do desenho e explicar os fenômenos. Nesse sentido, ela também é uma representação de cientista. Diferente da maioria das animações, ela não ocupa posição de submissão às figuras masculinas. Nesse sentido, essa figura quebra os padrões clássicos e estereotipados das meninas frágeis e indefesas, que prescindem da figura masculina para obter êxito e reconhecimento na produção do conhecimento científico.

Como as ideias de Marina e Peixonauta são complementares, não há antagonismo no trato do feminino e do masculino que cria estereótipos. Ela não aparece em contraste com a imagem de Peixonauta, pois também faz perguntas e oferece suas hipóteses. Neste contexto, o conceito de feminilidade está atrelado aos aspectos visuais da personagem e de sua personalidade. Marina é a personagem mais doce, bela e sorridente da série, o que também pode significar um ideal de feminilidade a ser perseguido. A única desvantagem da protagonista em relação ao Peixonauta está no uso de instrumentos utilizados pelo personagem no desenho. Mas, em muitos episódios, Peixonauta e outros personagens masculinos são colocados como 
colaboradores nas investigações nas quais Mariana é a principal inquisidora. Apesar da supremacia masculina na série, a presença de Marina reafirma a importância da mulher na ciência.

Zico é outro membro do trio de personagens principais. Ele é um primata originário da Ilha dos Macacos, um dos biomas do Parque das Árvores Felizes. Aparentemente, ele não pertence à "família dos grandes macacos", que inclui orangotangos, gorilas, chimpanzés, mas pelas características, também não pertence aos gibões. Como os macacos são sociais, a representação de Zico sem o seu grupo de origem, também é um efeito da animação. A cauda e os membros superiores de Zico são longos, como os macacos reais, mas ele aparece na animação quase sempre no chão, numa postura ereta demarcando uma antropomorfização do personagem. Em alguns episódios, como algumas espécies de macacos reais, ele é representado usando as pernas e braços para se locomover.

Embora os macacos sejam considerados como animais que possuem um aparato cognitivo vantajoso, comparado a outros, na série, Zico geralmente precisa de ajuda para entender as investigações. Dessa forma, o argumento de falta de capacidade cognitiva do macaco é usado no desenho como artifício para que Peixonauta e Marina sempre necessitem explicar os fenômenos para ele. Perante as pistas dadas, Zico sempre traça hipóteses mirabolantes. As cenas referentes ao modo como o personagem lida com o raciocínio científico é o viés humorístico da animação. Aliás, para Wasserman (2009), o riso é a interrupção de uma ordem conhecida. Nesse sentido, o raciocínio de Zico provoca o riso porque é, em muitas ocasiões, exagerado e absurdo. Assim, a eficácia do discurso veiculado no desenho se realiza, em muitas cenas, pela ingenuidade de Zico. Por fim, é importante ressaltar que Zico é um animal selvagem tratado como domesticado, reafirmando uma relação antropocêntrica da espécie humana sob os animais. Ele interage bem com os outros personagens, pode provocar empatia maior com o público infantil dadas as características já destacadas.

Apesar da temática ambiental ser um aspecto muito explorado no desenho, algumas informações são questionáveis como é o caso de diferentes animais, selvagens e domésticos e de diferentes biomas conviverem harmoniosamente em um mesmo parque. Nos filmes da $2^{\mathrm{a}}$ temporada da série, outros personagens contracenam com os protagonistas, auxiliando-os a transmitir suas mensagens e ideias. Eles podem ser divididos em dois grupos pela frequência de participação nos desenhos. No primeiro grupo temos, Dr. Jardim, Juca, Pedro, Agente Chumbo Feliz e Rosa. 
Dr. Jardim é o único adulto da série. É avô de Marina. Ele tem cabelos brancos, usa óculos e seu traje usual é um boné e um jaleco. Em alguns episódios, Dr. Jardim se destaca por sua disposição física, como por exemplo aparecer dependurado e de cabeça para baixo em árvores. Ele é veterinário e trabalha no Parque onde se localiza seu laboratório. Ali dispõe de tecnologia para solucionar problemas, em geral, identificados por Peixonauta e Marina. A curiosidade e a observação são marcas da personalidade de Dr. Jardim, Peixonauta e de Marina ressaltadas pela animação. A frequente simpatia do personagem funciona como um convite à aprendizagem, que, associada a recursos audiovisuais, chama a atenção das crianças para os temas científicos.

Dr. Jardim é uma representação de cientista mais próxima aos estereótipos mais frequentes nas mídias. Ele demarca a voz do sujeito-cientista mais experiente. Destaca-se nas cenas pelas definições, explicações, exemplificações e leitura que oferece aos personagens diante de temas mais complexos. Ele é a voz de autoridade sobre os fatos científicos evocados, sua voz é o "chamado da ciência". Dr. Jardim tem a grande responsabilidade de ratificar a posição do adulto que informa e forma. Assim, justifica-se a relevância de um adulto na animação pela autoridade que exerce na vida das crianças. A série apresenta Peixonauta e Marina como "cientistas de hoje e de amanhã" e Dr. Jardim como "cientista de hoje e de ontem". $\mathrm{Na}$ memória discursiva isso funciona como sentidos unívocos, como uma possibilidade de que todos podem ser cientistas.

Juca, Pedro, Agente Chumbo Feliz e Agente Rosa integram o elenco de apoio na série. Juca e Pedro são gêmeos e primos de Marina. Eles não investigam ou apresentam a pergunta que se desenvolve no enredo. Estão sempre envolvidos em alguns incidentes. Em alguns episódios, os problemas causados por eles precisam ser solucionados pelos protagonistas.

Já o Agente Chumbo Feliz é um peixe que, ao contrário de Peixonauta, vive em um ambiente aquático. Esse personagem é a representação de um mero. Assim como essa espécie, ele é caracterizado como um peixe grande, inofensivo e que vive sobre uma pedra. A animação se inspira na morfologia e comportamento da espécie para nomeá-lo. Aliás, no desenho "O caso do Chumbo Feliz", várias características relativas ao comportamento dos meros são informadas às crianças. No contexto da animação, Agente Chumbo Feliz é um peixe mais idoso que Peixonauta. Ele aparece como um sábio que tem uma fonte inesgotável de experiência empírica, um conselheiro nos momentos que não se encontram respostas para os problemas da ciência ou em episódios cuja tônica seja a formação moral. 
Outro peixe que aparece com frequência na série é Agente Rosa. Seu habitat é a água. O gênero dessa personagem emerge no nome - enunciado que cria uma representação feminina, expressa na simbologia dos grandes cílios, lábios carnudos e na cor rosa, culturalmente conhecida como uma cor feminina e delicada. Agente Rosa tem um papel secundário em relação ao protagonista da série, o que pode sugerir submissão do pensamento feminino as masculino. Nesse sentido, as duas personagens mais presentes na animação, ao mesmo tempo em que destacam o lugar do gênero feminino na ciência, reforçam alguns estereótipos e representações de um "ser" mulher na sociedade.

Os personagens factuais da $2^{\mathrm{a}}$ temporada da série são Abayomi e Júlia. Abayomi representa um índio que reforça o estereótipo que muitas crianças possuem dessa etnia, e Júlia, uma menina negra. Atribui-se a Abayomi a representação de "habitante da natureza" em seu estado puro, por viver em contato íntimo com a natureza. Nos filmes da animação aqui investigados, esses personagens aparecem uma única vez: Abayomi no Caso do indiozinho e Júlia no caso do amarelo. Dessa forma, esses personagens parecem construídos para atender às discussões do século XXI sobre a diversidade, mas as representações dessas diferentes etnias produzem hierarquias sociais que localizam crianças brancas no topo e negros e índios na base. A consequência disso para o público cativo dessa produção fílmica pode ser a naturalização de uma hierarquia étnica como um fato, uma vez que na série em questão a presença "politicamente correta" de negros e índios torna o desenho respeitável.

\section{Procedimentos do MÉtodo}

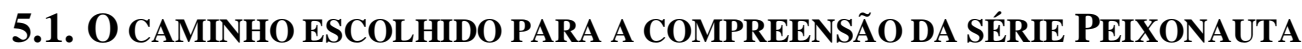

Para a realização deste estudo, foi feita a análise de alguns desenhos da série Peixonauta destinada ao público infantil. Foram analisados vinte e sete episódios da $2^{\mathrm{a}}$ temporada da série. As animações foram consideradas como documentos, pois servem como fontes de informações, indicações e esclarecimentos de conteúdos que elucidaram as questões desta investigação. Segundo Sá-Silva, et.al (2009), a análise documental tem como característica o exame minucioso de detalhes, o que requer investigar, seguir etapas, organizar informações e elaborar sínteses. 
Assim, o primeiro momento foi marcado pela busca dos episódios da série Peixonauta no site do youtube ${ }^{l}$, o que demandou: assistir a alguns filmes de animação da primeira temporada, com o objetivo de adquirir familiaridade com o desenho; conhecer a estrutura da animação e suas características. Procedeu-se da mesma forma com a segunda e a terceira temporadas. E, pela quantidade de desenhos apresentados na segunda temporada, preferiu-se analisar esse grupo.

Tendo assistido a todos os desenhos da segunda temporada, foi elaborada uma ficha técnica inspirada na pesquisa de Tomazi et. al (2009) sobre a divulgação da ciência em filmes de animação infantil. Neste trabalho, as categorias elencadas pelos autores giram em torno da concepção de ciência e de cientista. Optou-se por investigar as atividades dos cientistas e também a concepção de infância. Assim, para análise das animações, foram construídas categorias subdivididas em eixos temáticos os quais foram abordados com excertos das observações e interpretados com base nos fundamentos teóricos. Deste modo, definidas as categorias de análise, assistiu-se a todos os filmes da $2^{\mathrm{a}}$ temporada, pela segunda vez, seguindo um roteiro de observação, conforme o quadro a seguir:

Quadro 1 - Roteiro de observação da $2^{\mathrm{a}}$ temporada da série Peixonauta

\begin{tabular}{|l|}
\hline Concepção de ciência \\
\hline 1. O caminho utilizado pelos personagens para a construção do conhecimento \\
\hline 2. Aspectos históricos e sociais da construção do conhecimento científico \\
\hline Atividades dos cientistas \\
\hline 1. Concepção de atividade científica \\
\hline 2. Comunicação da ciência \\
\hline Concepção de infância \\
\hline 1. Estilo de vida \\
\hline 2. As crianças e o conhecimento científico \\
\hline
\end{tabular}

Fonte: Tomazi et al (2009)

Assim, para a análise das animações, foram realizadas anotações sobre os 27 desenhos da temporada, conforme categorias registradas nesse Quadro 1.

\footnotetext{
1 https://www.youtube.com/results?search_query=2a+temporada+da+s\%C3\%A9rie+peixonauta. Acesso em $20 / 02 / 2020$
} 


\section{RESUlTADOS E DISCUSSÕES}

Peixonauta tem, como proposta didática, a divulgação da ciência às crianças. Embora não seja produzido para fins escolares, os objetivos dessa série são educacionais e seguem uma tendência que se aproxima, em alguma medida, de concepções escolares de ciência.

Assim sendo, em relação ao caminho utilizado pelos personagens para a construção do conhecimento, foi possível observar que todos os episódios analisados apresentam um script dos problemas desvendados. Os episódios também são intitulados como "o caso" e, em cada um deles, os personagens têm uma missão. O "caso" já se coloca como uma eventualidade e não um processo. Quanto ao enredo, se desenvolve mediante um único caminho: apresentação das pistas e perguntas, elaboração de hipóteses, reunião de dados, interpretação dos resultados e conclusões. As pistas se constituem como uma situação problema - um pretexto para a narrativa. A repetição desse caminho em todos os desenhos parece servir como estratégia não só para a animação se eternizar na memória das crianças, como também para convencer que há uma metodologia adequada para resolver os problemas científicos.

Com referência à construção do conhecimento pelos cientistas da série, o mesmo ocorre pela experiência empírica. Contudo, a experimentação não aparece como meio de construir conhecimentos. A imaginação não é um traço realçado no perfil dos personagens.

Na maioria das animações investigadas, as definições dos conceitos científicos advêm das vozes de Peixonauta e de Marina, que encarnam a infância de modo que eles próprios elaboram e respondem às questões. Em várias cenas, assume-se o não entendimento do conhecimento científico, principalmente por Zico, indicando a dificuldade que as crianças teriam com informações consideradas mais complexas. Esse dado corrobora com as investigações de Bueno (2012) ao destacar que as crianças são costumeiramente representadas, quando se trata de divulgação científica, sempre em déficit, atrasadas, inócuas em suas próprias invenções de conhecimento e de mundo. Para a autora, os materiais de comunicação científica apoiam-se no que as crianças não sabem, prevalecendo a ideia de que são tábulas rasa.

A esfera de produção de Peixonauta é midiática e os textos verbais são de fontes secundárias, ou seja, não é um cientista que produz o texto ou um especialista em divulgação científica para crianças. A maioria dos textos verbais apresenta uma estrutura que parte da descrição para a definição. Dessa forma, a linguagem verbal não passa por um tratamento específico da esfera de divulgação científica para as crianças. Mas, há uma adequação da linguagem dos termos científicos para que se tornem compreensíveis ao público. Assim sendo, 
embora predominem nos desenhos termos do universo cotidiano, estão presentes palavras e expressões científicas que são explicadas às crianças quando aparecem. Não se identificou o uso de analogias e metáforas nos filmes analisados. Em todas as animações, as perguntas estão presentes. A estratégia de "chamar a atenção do público" por meio de frases de efeito ou musicalidade visa manter a criança atenta ao desenho. Nesse sentido, a série é um produto de dupla intencionalidade: a de seduzir o espectador e ensinar com determinada intencionalidade comunicativa corroborando os estudos de Ramos (2014).

A narrativa da série parece levar às crianças a ideia de que só poderão confiar em suas respostas se adotarem uma "vivência científica". Essa "vivência científica" é baseada na curiosidade e observação. Esta última se constitui como uma constatação das características dos objetos, animais ou fenômenos. A observação em Peixonauta aparece como exercício de olhar o mundo para identificar suas partes e nomeá-lo. Nesse caso, observar requer desenvolvimento sensorial para aprender um "vocabulário científico". Portanto, a observação na atividade científica implica observar objetos, fatos e fenômenos com lentes específicas que permitam relacionar os diferentes fatores observados em um marco de conhecimento (PUJOL, p. 112, 2003).

Com efeito, os personagens "redescobrem" o já conhecido pela ciência, mostrando um caminho, uma sequência de etapas preestabelecidas. Para isso, em todos os episódios, Peixonauta e Marina interagem com os animais do parque com perguntas do tipo: vocês viram alguma coisa? Notaram algo estranho? Aconteceu algo por aqui? No caso do peixe esquisito, Marina utiliza a palavra investigação mais de uma vez para se referir às descobertas.

Assim, a série Peixonauta mostra às crianças que os personagens precisam explorar o mundo a fim de conhecê-lo melhor. Mas, o caminho percorrido por cada personagem para a construção do conhecimento é diferente: enquanto Zico sempre se precipita em suas conclusões, Peixonauta e Marina sempre se baseiam em fontes dignas de confiança, caracterizando uma concepção de pensamento científico desses personagens na animação. Dessa maneira a animação reafirma, normaliza a representação de construção de conhecimento científico, ainda vigente, pois busca menosprezar as precipitações, os equívocos, o processo de tentativa e erro, parte da própria prática de exploração científica.

Entretanto, Peixonauta e Marina estão sempre com Zico valorizando a ação coletiva, considerando as suas opiniões e colaborando para a adequação de suas respostas. A docilidade de Marina e a tranquilidade de Peixonauta reafirmam o respeito às normas de comunicação 
utilizadas para fazer prevalecer ideias de equidade. O confronto de pontos de vista e negociação para a construção de um consenso não estão presentes nos desenhos investigados.

Quanto aos temas da série de desenhos estudados, o vestuário dos personagens e vocabulário tudo é atemporal. Também não há evidências de aspectos históricos e culturais na construção do conhecimento. Na maioria dos desenhos, os personagens resolvem a "missão" sem pressupostos e/ou referências a outros estudos.

As investigações dos personagens-cientistas se dão, principalmente, no parque, local onde moram. Observa-se aí o apelo da animação para as questões ambientais. Aliás, os títulos da $2^{\mathrm{a}}$ temporada da série, sugerem o predomínio de temas relacionados à biologia e temas transversais. Além dos conceitos científicos abordados, os personagens interagem em um contexto de valores, ideias, objetos e representações sobre os mais diversos temas. A série objetiva ensinar distintos valores, atitudes e comportamentos. Para Coll (1986), o valor se constitui como um princípio normativo que preside e regulamenta o comportamento das pessoas em qualquer momento e situação. "Os valores fazem referência a como cada um pensa que deveriam ser as relações entre as pessoas, entre os elementos que representam a sociedade e as relações entre sociedade e natureza" (PUJOL, p. 269, 2003). O conceito de atitude é definido por Coll (1986), como uma tendência a comportar-se de maneira persistente e consciente, ante estímulos e situações concretas, exteriores ou interiores.

Nesse sentido, dialogar, interagir e trabalhar em grupo são atitudes necessárias para que a cooperação se concretize. Essas ações estão presentes em todos os desenhos da série. Entre muitos valores e atitudes cultivados pelos criadores da animação, citam-se: autonomia, responsabilidade, cooperação, sustentabilidade, preocupação ambiental, curiosidade, perseverança, interesse pelas questões ambientais, disposição afetiva e motivação para aprender, etc. Assim, os desenhos analisados cumprem não só a função de informar, conforme destacado por Ramos (2014), mas também a de educar para a ciência considerando-se atitudes, valores e normas essenciais para a aprendizagem dessa linguagem. Afinal, essa animação se destaca por incentivar as crianças a atitudes autônomas e responsáveis para a vida em sociedade.

Observa-se que o foco da maioria dos episódios está na descrição dos fenômenos biológicos. O objetivo principal do conhecimento científico é a melhoria da qualidade de vida e a utilização desse conhecimento para o bem de todos no parque. Nos desenhos investigados, todos os casos são solucionados. Portanto, há uma “concepção social pragmática e utilitária do 
conhecimento e que compreende quase exclusivamente as Ciências Exatas, da Vida e suas Tecnologias" (GUIMARÃES, 2001, p. 76).

Alguns desenhos, apresentam os personagens buscando informações sobre o assunto investigado em computadores e livros. Os registros das informações são realizados com máquina fotográfica, lápis e papel. Balança, computador, lupa, pipeta, termômetro, velocímetro, relógio-comunicador são alguns dos instrumentos mostrados nas animações da $2^{\mathrm{a}}$ temporada. São destacadas também, como atividade dos cientistas as invenções tecnológicas para a resolução dos casos. Contudo, o uso desses instrumentos não diminui a imagem de ciência a-histórica, pois não revela as transformações do pensamento científico de acordo com os contextos sociais, culturais, políticos e econômicos nos quais estão inseridos o trabalho científico. Mas, em alguns episódios da série, há referências a outras dimensões temporais. Por exemplo, No caso do navio pirata e No caso do indiozinho flashs do passado indicam a importância de se preservar a história e seus objetos.

Deve-se destacar, ainda, nessa série que, em todos os episódios, os protagonistas trabalham juntos para solucionar os problemas. Infere-se que a ênfase no trabalho em grupo seja uma forma de destacar a produção coletiva como um aspecto crucial da construção do conhecimento científico, mas ele também não aparece sintonizado com o contexto históricosocial.

Dos vinte e sete episódios analisados, nenhum faz referência a nome de qualquer cientista real nem menção às fontes. Embora Peixonauta seja apresentado como um inventor, em nenhum episódio, ele aparece construindo seus aparatos ou discutindo sua utilização. Contudo, inventar e dar novo uso aos objetos é o que crianças fazem em demasia. Nesse aspecto, a série perde a oportunidade de alimentar essa característica das crianças e mostrar a elas que as invenções são inerentes ao conhecimento científico e cultural.

Fica claro na animação que, para ser um cientista, não é preciso ter habilidades excepcionais. Contudo, a curiosidade e a persistência são os aspectos mais ressaltados na personalidade dos personagens. De outro modo, apesar do protagonismo de Marina e da aparente autonomia das outras crianças da série, o que reverbera na animação são as ideias do que os criadores da série acreditam ser o ponto de vista das crianças.

As ideias de ingenuidade, romantização da infância feliz da criança, autonomia e liberdade são características que a série procura assegurar. No entanto, encontram-se nas animações representações de crianças obedientes e bem comportadas, semelhantes àquelas de 
séculos passados. Nesse sentido, faltam na série, desenhos que saiam da dicotomia certo/ errado e que deixem margem para a criança pensar por si só, possibilitando-lhe a oportunidade de se manifestar sobre os fatos e fenômenos apresentados na animação.

Ademais, as questões cognitivas e emocionais são evidenciadas em detrimento às econômicas, criando uma concepção de infância diferente desta que se apresenta no século XXI. Mas, esse é um aspecto positivo da série, pois as crianças representadas não consomem produtos de marca ou alimentos industrializados. As brincadeiras são tradicionais e em grupo. Em alguns episódios, os personagens são representados brincando de cabra-cega, pula-pula, corrida, andando de bicicleta, carrinho de rolimã, patins, jogando bola, e malabarismo. Brincadeiras que algumas crianças nunca tiveram ou terão contato, diante do contexto atual, em que são acionadas sobretudo pelas mídias e tecnologias em geral.

Por outro lado, os pais e a escola não são mencionados no desenho. Mas, a tutela do Dr. Jardim se faz notar ao regular o tempo e algumas atividades das crianças. Geralmente quando elas não estão brincando, estão participando de alguma atividade designada por Dr. Jardim, mas sem cobranças ou punições. Em O caso da noite iluminada, Dr. Jardim sai em busca das crianças que não chegaram em casa no horário estipulado.

Em suma, os personagens que representam os cientistas são investigadores por natureza. Eles sempre querem solucionar os problemas. Para tanto, eles precisam de objetos, espaço e tempo para que reajam aos estímulos do ambiente em que vivem. E as crianças representadas em Peixonauta elaboram perguntas sobre os animais e fenômenos do ambiente sem mediação dos adultos. Dessa forma, nos desenhos analisados, o conhecimento científico se baseia em fatos da natureza e as descobertas feitas pelas crianças partem dos sentidos.

\section{CONSIDERAÇÕES FINAIS}

Tendo por base os pressupostos teórico-metodológicos indicados, a análise da $2^{\mathrm{a}}$ temporada da série Peixonauta apresentada neste trabalho tem como propósito investigar as características do gênero de divulgação científica dessa animação. Como produto da indústria do entretenimento para crianças, a animação se vale do discurso didático e midiático utilizando a linguagem das ciências para tal empreitada. $\mathrm{O}$ conhecimento científico apresenta-se como um saber estável, não problemático, inquestionável, o que contrasta com o cenário próprio do saber da investigação, corroborando os estudos de Ramos (2014). A divergência também não é um aspecto explorado pela animação. 
Ao contrário dos estudos de Bueno (2007), há três representações de cientistas que se aproximam e se afastam dos estereótipos presentes na mídia. Mas, laboratórios e criações mirabolantes permanecem no imaginário dos produtores como uma marca do trabalho científico. Os personagens sempre trabalham em grupo e os experimentos não fazem parte do roteiro da série. Os personagens que representam os cientistas destacam-se pela curiosidade, mas percebe-se a tentativa de mostrá-los com uma vida típica de qualquer outra criança. As crianças auxiliam o avô nas tarefas do parque remetendo a ideia de que os cientistas são pessoas comuns. O conhecimento está presente nos personagens que representam os gêneros masculinos e femininos, mas apenas Peixonauta é detentor de tecnologias para resolver os problemas. O enredo se desenvolve a partir de uma concepção positivista da ciência, associada a questões que são colocadas aos protagonistas. As ciências da natureza são abordadas na maioria dos desenhos relacionadas a valores e atitudes, deixando-se de lado os interesses da construção do conhecimento científico, a competição e a ideia de progresso.

Nos desenhos analisados observou-se que as os conhecimentos científicos da atualidade não constituem o principal critério para a o enredo da história. O que parece mais evidente são os temas, que estão longe da mídia e da vivência das crianças, mas instigam curiosidade. $\mathrm{O}$ aspecto lúdico e a finalidade didática também parecem fazer parte desses critérios. Assim, em Peixonauta, os textos verbovisuais de ciência parecem construídos com o objetivo de ensinar as crianças fatos e fenômenos da ciência a partir de definições. Nos filmes de animação analisados, a ciência não está associada a catástrofes, tragédias, controvérsias da ciência ou notícias desagradáveis devido a uma romantização das ciências, naturalizada como prelúdio de salvação, e reproduzida pelo desenho. Embora a vida dos animais seja um aspecto excessivamente explorado nesses materiais, informações sobre os bichos que estão próximos às crianças são pouco frequentes na animação. Nesse sentido, prima-se pelo viés espetacularizado da ciência. As falas dos personagens sugerem uma reformulação de um discurso enciclopédico.

Inspirado em um assunto ainda pouco investigado, este breve estudo acerca da série Peixonauta se fez necessário principalmente para conhecer um pouco dos traços da comunicação científica para crianças nas animações e as tendências dessa produção. Assim, a perspectiva da presente investigação é também (re) conhecer que Peixonauta é uma animação que destaca a curiosidade como um elemento importante que precisa e pode ser alimentado na infância, assim como a autonomia e liberdade das crianças de formularem perguntas e ir em 
busca de respostas. É um desenho que destaca o papel do feminino e da importância da sustentabilidade e preservação da natureza. Reitera-se, assim, a importância dessa animação como possibilidade de promoção da linguagem de divulgação científica para crianças.

\section{REFERÊNCIAS}

ALMEIDA, Sheila Alves de. Interações e práticas de letramento mediadas pela revista Ciência Hoje das Crianças em sala de aula. Tese - Universidade de São Paulo - Faculdade de Educação, São Paulo, SP, 2011.

ALMEIDA, Sheila Alves de. Divulgação científica para crianças: uma análise de artigos das revistas Ciência Hoje das Crianças e Recreio. Revista Ciências \& Ideias, v. 11, p. 01-18, 2020.

ALMEIDA, Sheila Alves de. Cenas de leitura da Ciência Hoje das Crianças: Modos de uso e apropriação da revista em sala de aula. Educação Em Revista (Online), v. 34, p. 1, 2018.

BUENO, Christiane Cardoso. https://paralelas.wordpress.com/2014/02/13/a-ciencia-nosdesenhos-animados. Acesso em 01/06/2020

BUENO, Christiane Cardoso. Imagens de crianças, ciências e cientistas na divulgação científica para o público infantil. Dissertação - Universidade Estadual de Campinas Instituto de Estudos da Linguagem, Campinas, SP. 2012.

COLL, César. Psicologia e Currículo. São Paulo: Ática, 1996

GATTI JUNIOR, Wilian.; GONÇALVES, Marilson Alves.; BARBOSA, Ana Paula Franco Paes Leme. Um estudo exploratório sobre a indústria brasileira de animação para a TV.

Revista Eletrônica de Administração, v. 20, n. 2, 2014.

GATTI JUNIOR, Wilian.; MARIETTO, Marcio Luiz. Como Pode um Peixe Vivo Viver Fora do Brasil? O Caso Peixonauta. Revista Ibero-Americana de Estratégia, v. 16, n. 4, 2017.

GIERING, Maria Eduarda. A divulgação científica midiática para crianças e os fins discursivos. Revista do GEL (Araraquara), v. 5, p. 109-128, 2008.

GREEN, Bill C. Alienígenas na sala de aula. In: SILVA, Tomás Tadeu da. Tomaz Tadeu da Silva (org.) Petrópolis RJ: Vozes, 1995.

GUIMARÃES Eduardo. A Ciência entre as Políticas Científicas e a Mídia. In: Produção e Circulação do Conhecimento, Campinas: Pontes, 2001.

HOFFMANN, Adriana Fernandes. As mediações de sentidos das crianças sobre os desenhos animados. Educação e Comunicação, n. 16. 2002

KINDEL, Eunice. A natureza no desenho animado ensinando sobre homem, mulher, raça, etnia e outras coisas mais... Tese. Porto Alegre, Universidade Federal do Rio Grande do Sul, 2003. 
MASSARANI, Luisa. (Org.) . O pequeno cientista amador - a divulgação científica e o público infantil. 1. ed. Rio de Janeiro: Vieira \& Lent, 2005. v. 1.89 p.

MASSARANI, Luisa. La divulgación científica para niños. In: Quark: periodismo científico en un mundo diverso, $n^{\circ} 34$, outubro-dezembro/2007. Disponível em http://www.prbb.org/quark/17/017040.htm. Acesso em 9/06/2021.

MESQUITA, Nyuara Araújo da Silva; SOARES, Marlon Herbert Flora. Barbosa. Visões de ciência em desenhos animados: uma alternativa para o debate sobre a construção do conhecimento científico em sala de aula. Ciências \& Educação. Bauru, vol 14, 2008.

PUJOL, Roma Maria. Didáctica de las Ciencias em la Educación primaria. Madri. Sintesi, 2003.

RAMOS, Rui. Construção dos objetos de discurso em artigos mediáticos de divulgação científica para crianças. Redis: revista de estudos do discurso, n ${ }^{\circ} 3$, ano 2014.

SÁ-SILVA, Jackson Roni; ALMEIDA, Cristóvão Domingos; GUINDANI, Joel Felipe. Pesquisa documental: pistas teóricas e metodológicas. Rev. Bras. de História \& Ciências Sociais. n. I, p. 1-15, jul., 2009.

SIQUEIRA, Denise da Costa Oliveira. A ciência na televisão: mito ritual e espetáculo. ANNABLUME, São Paulo, 1999

TOMAZI, Aline Luiza; PEREIRA. Aline Juliê; SCHÜLER, Cristiane Müller; PISKE, Karin; TOMIO, Daniela. O que é e quem faz Ciência? Imagens sobre a atividade científica divulgadas em filmes de animação infantil. Ens. Pesqui. Educ. Ciênc. Vol 11. Belo Horizonte. 2009.

TOROK. Simon. Falar de ciência para crianças: algumas dicas. In: MASSARANI, Luisa (Org.). Ciência \& Criança: A divulgação científica para o público infantoi-juvenil. Rio de Janeiro: Museu da Vida, 2008. p. 49-54.

VIZACHRI, Tânia Regina. Animais humanos ou humanos animais? Um estudo sobre a representação dos animais antropomorfizados nos filmes de animação. 2014. Dissertação, Universidade de São Paulo, São Paulo.

WORTMANN, Maria Lúcia Castagna.; RIPOLL, Daniela.; POSSAMAI, Laís. Educação Ambiental corporativa para crianças: analisando a animação Peixonauta do Discovery Kids. Perspectiva (UFSC), 2012.

\section{Agradecimentos}

Pró-Reitoria de pesquisa da Universidade Federal de Ouro Preto. 